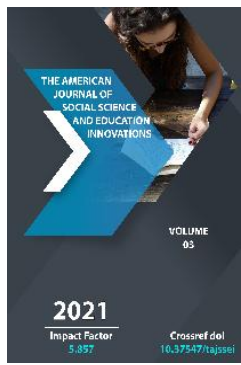

Journal Website: http://theamericanjour nals.com/index.php/taj ssei

Copyright: Original content from this work may be used under the terms of the creative commons attributes

\title{
Application Of Interactive Methods For Studying The Value of "Time" In Primary School
}

\author{
Oksana Savenko \\ Lecturer, Department Of Mathematical Analysis, Termiz State University, Uzbekistan \\ Gulnara Djavlieva \\ Lecturer, Department Of Algebra And Geometry, Termiz State University, Uzbekistan
}

\section{ABSTRACT}

To increase the effectiveness of the lessons, for a deeper interest in the subject of mathematics, the authors disclose the use of interactive methods for studying the value of "Time" in primary grades. The article also talks about how people learned to measure time.

\section{KEYWORDS}

Mathematics, teaching methods of mathematics, Interactive method, insert method, time, Time measurements units, method of studying the "Time" value.

\section{INTRODUCTION}

To increase the effectiveness of the lessons, for a deeper interest in the subject of mathematics, the authors disclose the use of interactive methods for studying the value of "Time" in primary grades. The article also talks about how people learned to measure time.

In the education system of the Republic of Uzbekistan, large-scale reforms are being carried out in accordance with the goals and objectives of the National Program for Personnel Training. One of them is the development of pedagogical technology, a new direction in the world of pedagogical science.Interactive learning is a special form of organizing cognitive activity that has specific goals. One of these goals is to create optimal learning conditions, such as in which the learner feels his or her intellectual worth, which makes the learning process effective. The interactive methods are based on a competent discussion technique.

Let's consider the application of these methods when studying the value of "Time" in primary grades. 
1. The concept of an interactive method. Model lesson.("Thief" - Challenge, Comprehension, Reflection).

The lesson begins with a discussion of development No.1 "How do we learn?" The attention of students is drawn to how a person assimilates information. So, for example, when reading, only $10 \%$ is remembered, $20 \%$ is absorbed through hearing, visually - 30\%, assimilation of information with the participation of sight and hearing at the same time - 50\%. When discussing information with others - 70\%, personally experienced information is assimilated by $80 \%$, while teaching others, we ourselves are able to assimilate $95 \%$ of the information.

2. Formation of ideas about time.

This part of the lesson plan begins by explaining the cluster development method. Having explained this method, we proceed directly to the formation of ideas about time.

a) Challenge- "Cluster" on the topic "Time" looks like this: 
The American Journal of Social Science and Education Innovations (ISSN - 2689-100x)

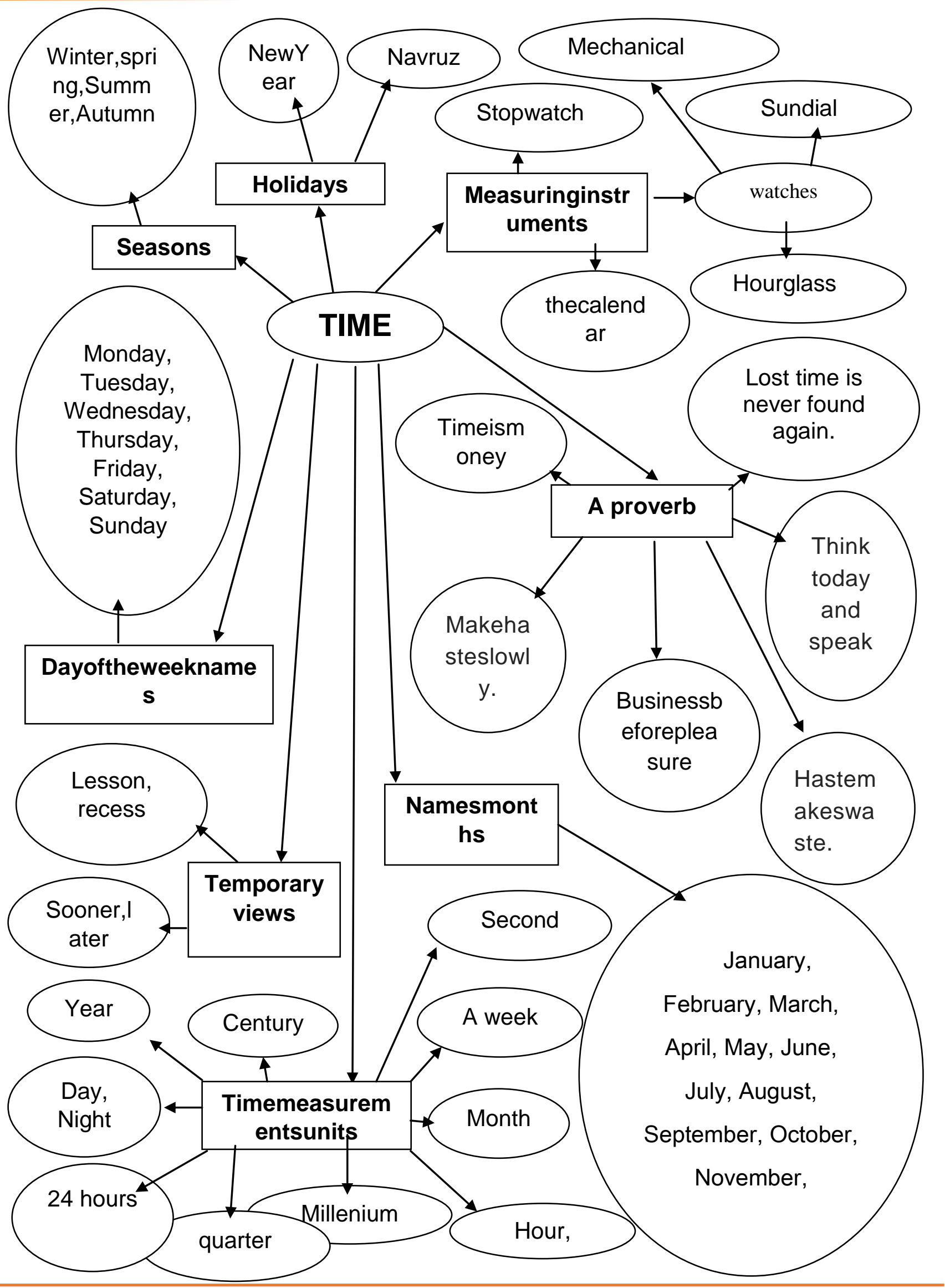


b) Comprehension - "Categorical image". Everything that the students have worked out at the stage of calling the construction of the "Cluster" on the topic of time, we bring into a certain system.

Time measurements units: Second, minute, hour, day, week, month, quarter, year, century, millennium (millennium).

Instruments for measuring time, i.e. watches: mechanical, electronic, solar, sand, etc.

Names of the days of the week: Monday, Tuesday, Wednesday, Thursday, Friday, Saturday, Sunday.

\section{How did people learn to measure time?}

Even in ancient times, people noticed that the change of day and night occurs after a certain period of time. The alternation of work and rest in his activities is closely related to this phenomenon. This is how the concept of 24 hours, the first natural unit of time measurement, appeared.

In accordance with the number of fingers on one hand, then on two hands, a five-day "small week" was born at the beginning, and later a ten-day "big week". Simple observations of the periodically changing appearance of the moon - phases - led to the second natural unit of time measurement - the month, i.e. a period of time from one new moon to the next. Since ancient times, the moon has been called a month not only in Russian, but also in other European and Eastern languages. On the basis of the day and month, the first lunar calendars of the ancient Chinese, Babylonians and other peoples were compiled. A month was equal to one time 29.5 days. The seven-day week was established as a period of time from one lunar phase to another, from the new moon to the first quarter.

With the transition of people from a nomadic to a sedentary lifestyle, with the development of agriculture, the need arose to distinguish the frequency of alternation of spring, summer, winter and autumn associated with the movement of the sun. A larger unit of time has appeared - the year. This is how the solar calendar was gradually created.

The length of the year was determined at the beginning very uncertainly. The ancient Egyptians, for example, took for a year - a period of time from one flood of the Nile to the next, and only then - from one pre-dawn rise of the bright star Sirius to another. Gradually, they set the length of the solar year to 365 days. Due to the fact that the measurement of time was based on the rotation of the Earth around its axis, great difficulties arose in the construction of calendars. After all, neither the lunar month nor the solar year contain a whole number of days. The duration of the first is 29 days 12 hours 44 minutes and 3 seconds, and the second - 365 days 5 hours 48 minutes 46 seconds. Therefore, a conditional calendar month with a whole number of days and a conditional calendar year have long been introduced, striving to ensure that the year differs as little as possible from the true year (the duration of the complete revolution of the Earth around the sun).

Over the centuries, there have been repeated attempts to improve the calendar. One of the most important calendar reforms in antiquity was undertaken in $46 \mathrm{BC}$. at the direction of the Roman emperor Julius Caesar. The calendar, created then by a group of scientists led by the astronomer Sozigen, was named 
Julian in honor of Caesar. According to the Julian calendar (now - "old style"), the year contained 365 days, but every fourth year high - 366 days. Since the average length of the year was, thus, 365 days 6 hours, the calendar year turned out to be longer than the solar one by 11 minutes 14 seconds. Every 128 years, the discrepancy accumulated in the whole day, and when in the XVI century. Since a new calendar reform was undertaken, this discrepancy was already 10 days.

On the recommendation of a commission of specialists, Pope Gregory XIII approved in 1582 a draft of a new calendar proposed by the Italian scientist Aloysius Lilio. This calendar is called Gregorian ("new style"). The day after October 4, 1582, was declared October 15 to correct the 10-day error that had accumulated so far. The new style differs from the old one in that every 400 years there are 3 less leap days, namely, years ending in two zeros are considered leap years when they are divisible by 400 without a remainder. Forexample, 1600, 2000 areleapyears, 1700 , 1800, 1900 simple.

Thus, the difference of 1 day does not accumulate over 128 years, as in the old style, but over 3300 years. The calendar year of the new style has become much closer to the true solar year.

For religious reasons, many non-Catholic states have long resisted the introduction of the new style calendar. In the XX century.the discrepancy between the old and the new style was already 13 days. Therefore, when after the Great October Socialist Revolution a new style was introduced in our country, we had to count the day of February 2, 1918, February 15.
Many calendar terms originate from the ancient Romans. The very word "calendar" in Rome meant a book of debts. Debtors paid interest on the day of calendars, which was the name of the first day of each month. The first month of the year was named January in honor of the two-faced god Janus, one face of which was turned forward (to the future, to the new), and the other - back (to the old, past); February is supposed to come from the Latin februm - purification. It was a month of religious repentance. The month of March was named in honor of the god of war Mars. In April, the trees open buds, the word "aperire" means "opening". The spring month of May was named for the god Majus, the patron saint of growth, and June for the sky goddess Juno. July and August were named after the Roman dictator Julius Caesar and the emperor Augustus. The original Roman year consisted of 10 months. The last four of them were called:

September - "seventh" (September), October - "eighth" (October), November - "ninth" (November), December - "tenth" (December).

The names of the days of the week in some languages have long been associated with the names of celestial bodies: Sun, Moon, Mars, Mercury, Jupiter, Venus. "Week" (not to do) was called in the old days, and in some Slavic languages and is still called, a day of rest.

The first day after the "week" was called "Monday", the second "Tuesday", the fourth "Thursday", the fifth - "Friday". The middle of the week was called Wednesday. "Saturday" comes from the Hebrew "Sabbath" - rest, rest. According to the Bible, this day was "God's day of rest." The name of Sunday is associated with the religious belief in the mythical "resurrection". 
The calendar of the new style, which is now used in almost all countries of the world, is also not devoid of major shortcomings, of which the most important are: the inequality of months, quarters of the year, and six months and the lack of consistency between different units of time measurement. So, for example, neither a month nor a year has a whole number of weeks, a month does not have a constant number of days, the same days of the month fall on different days of the week, etc. Therefore, in the last decade, the question of a new reform and the introduction of a single world calendar has been raised. Several projects of the new calendar have been developed at the initiative of the UN. For one of these projects, the year consists of 4 quarters (quarters) of 91 days. The first month of each quarter starts on Sunday and has 31 days, the second month of 30 days starts on Wednesday, the third on Friday. The 365th day of each year is not included in the weeks and months, it is left without number and is declared "the day of peace and friendship of peoples". Also, the day added in high-rise years is left without number. After approval by the UN member states, the new international calendar will be applied in all countries of the world.

Names of months of the year: January, February, March, April, May, June, July, August, September, October, November, December.

Proverbes about time: Time is money; Lost time is never found again; Haste makes waste; Think today and speak; Business before pleasure; Make haste slowly.

c) Reflection at this stage - the Insert Strategy is used, each student gets development No. 4 "How did people have learned to measure time?"

Students carefully read the text. In the process of reading, they make a note with a pencil on the fields, i.e. against each paragraph test. OntheboardhangsthetablewithInsertsigns.

Table Insert

\begin{tabular}{|c|l|l|l|l|l|l|}
\hline SignsInsert & Group & $\begin{array}{c}\text { Meaningofsi } \\
\text { gns }\end{array}$ & 1 team & 2 team & 3 team & 4 team \\
\hline $\mathbf{v}$ & & & & & \\
\hline+ & & & & & \\
\hline- & & & & & & \\
\hline
\end{tabular}


Then the students of each team among themselves, discuss the signs of the insert, sum up for each sign and fill in the general table. For example: in the 1st command, the "V" sign corresponds to 15, the "+" sign 21, the "-" sign - 3, the "?" - 2.

All other commands do the same. Then one representative from each team goes to the board and talks about the information received on the insert signs. Special attention is paid to the sign "-" and "?".

At the end of the discussions, the teachertrainer summarizes everything that was said for all the teams and explains in detail everything that turned out to be unclear ("?") And what was contrary to what the students knew ("-").

Thus, through the "Insert" strategy, both individual work (each student read the text himself and made notes of insert signs) and group work in the classroom is carried out.

3. Next, we proceed to point 3 of our plan, namely, the method of studying the "Time" value.

A "Methodological scheme for the study of quantities" is posted on the board, which is uniform for the study of any quantity studied in mathematics lessons in elementary school: length, time, mass, capacity, area.

Methodology "Scheme" for studying quantities:

1. Clarification and clarification of children's ideas about this quantiti (referring to the child's experience).

2. Comparison of homogeneous quantities (visually, with the help of sensations, overlapping, by using different measures).

3. Acquaintance with the unit of measurement of the given quantity and with the measuring device.

4. Formation of measuring ability and skills.

5. Addition and subtraction of homogeneous quantities, expressed in units of one name (in connection with and with the solution of problems).

6. Acquaintance with new units of quantity, in close connection with the study of numbering by concentrates, conversion of homogeneous quantities into others and vice versa.

7. Addition and subtraction of values expressed in units of two items.

8. Multiplication and division of a quantity by a number.

Particular attention is paid to the introduction of new units of time, respectively, the study of the concentrates of numbers (ten, hundred, thousand, multi-digit numbers).

The lesson ends with an excursion dedicated to the scientific heritage of the great Central Asian scientists who made their unique contribution to the improvement of the measurement of time, in the creation of accurate calendars. These are, first of all, Muhammad al-Khorazmi, Abu RaykhonBeruni, Umar Khayyam, Nasreddin at-Tusi, Ulugbek, Giyasiddinal-Kashi and others.

\section{REFERENCES}

1. Z.G.Tadjieva, G.R.Javlieva, O.V. Savenko. Elements of historicism and methods of teaching mathematics in elementary grades. (tutorial). Tashkent - 2021, - 390 pages.

2. O. V. Savenko. Some of the most pressing issues for the lifelong learning 
system.International scientific journal "Science and World", No. 3 (79), 2020, Vol. II.Russia, Volgograd 2020. 63 - 66 pages.

3. G.R.Javlieva. Development of productive thinking in younger students. Professional education and society. 2019. No. 4 (32). -p. $116-130$.

4. Farfieva, K. A. (2021). Theoretical Fundamentals of Scientific And Innovative Thinking In Adolescents. The American Journal of Social Science and Education Innovations, 3(04), 431-437. 